\title{
Move Over, Strategic Plan: Make Way for the Culture Plan!
}

\author{
Clarence Chant
}

$\mathrm{C}$

ulture, as defined by the Merriam-Webster dictionary, is "the beliefs, customs, arts, etc., of a particular society, group, place, or time". ${ }^{1}$ This definition applies to professional groups, including pharmacists, the institutions where they work, and even the Canadian Journal of Hospital Pharmacy (CJHP), which is "never closed, always renovating"! ${ }^{2}$ In the various pharmacy curricula across the country, recent focus has been on raising awareness of the diverse backgrounds and cultures of patients and on teaching students how to deal with these characteristics in order to become better practitioners. However, the importance of understanding the culture of pharmacists themselves has not yet gained widespread traction in either undergraduate curricula or professional development course offerings. The importance of understanding our own culture (and also that of our team members, such as physicians and nurses) can be inferred from examples in the private sector, where the catch-phrase "culture eats strategy for breakfast" has become popular. Attributed to Peter Drucker, a US management consultant, this phrase has been adopted by many companies, including the Ford Motor Company. ${ }^{3}$ It has been interpreted to mean that no matter how well an organization defines its mission and strategic plan, implementation will not succeed unless the mission and plan are accompanied by, and consistent with, an understanding of the organization's culture. Alternatively, a company will succeed, even in difficult economic times and even when it encounters significant obstacles, if its culture and values are clear. Furthermore, there is some preliminary literature suggesting that organizational performance may in fact be contingent upon culture. ${ }^{4}$

Several recent articles in the CJHP have directly or indirectly addressed the notion of culture. Rosenthal and others ${ }^{5}$ attempted to study the professional culture and personality traits of hospital pharmacists in Canada. The authors administered a standardized tool (the Organizational Culture Profile) to gain insight into hospital pharmacy culture and the Big Five Inventory to measure respondents' personality traits. Relative to previously published data, the 401 hospital pharmacists who responded to the survey perceived greater value in supportiveness, competitiveness, and stability, and less value in innovation, social responsibility, performance orientation, and reward orientation. When respondents' culture profile and personality traits were correlated with certain

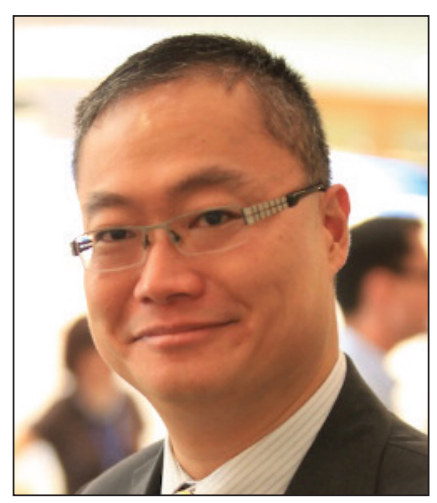
"cultural antecedents", there appeared to be an interaction between level of education and the innovation and competitiveness domains. Associations with certain cultural domains were also seen for years and geographic regions of practice. The issue of how the current culture of social media is being used in pharmacy practice was discussed in another recent $C J H P$ article. ${ }^{6}$ Indeed, $C J H P$ will soon be publishing a series of papers describing pharmacy practices around the globe, which no doubt will highlight some important cultural differences and how they may have shaped practice.

Rosenthal and her colleagues should be commended for their recent work, which adds to their previous work on the culture of community pharmacists. ${ }^{7}$ In that earlier study, the culture of community pharmacists was found to be product-focused, with pharmacists seeing themselves primarily as "medication dispensers". The small body of literature on the culture of our profession was reviewed by Jacobs and others, ${ }^{8}$ who found only a handful of studies documenting the culture of pharmacists, and those primarily for community pharmacists. Recent studies such as the ones cited above ${ }^{5-7}$ are important first steps that will help us to discover what "makes us tick" and, therefore, assist in future planning and strategies targeted toward changing pharmacists' behaviour. It is important for us, as individual pharmacists, and 
for the institutions in which we practice, to understand our own culture. Too often, pharmacy leadership attempts to implement changes affecting front-line pharmacists (e.g., computerized prescriber order entry) without a good understanding of the culture, which leads to little change or, worse yet, complete failure. It is not just the culture of the target audience that is important, but also the culture of the change initiator, as the beliefs and values of pharmacists leading the change could also contribute to the success or failure of the effort. Many of us have led practice change projects that have been tremendously successful because somehow the culture of the target population changed to become congruent with the intent of the project. For example, according to the previous culture in the intensive care unit (ICU), hyperglycemia was an expected part of critical illness and not worthy of clinicians' attention. As such, successful implementation of tight glucose control in the ICU was achieved only when the belief system of the nursing staff was changed from "We don't care about blood glucose because hyperglycemia is natural and not a problem" to "There is evidence that treating hyperglycemia is an important part of making my patients better"!

In most institutions and pharmacy departments, the culture is often neither known nor defined, and little to no effort is spent to create, define, or change it. At the same time, pharmacists, especially those working in a hospital environment, are frequently involved in leading or participating in many large-scale change processes, such as quality improvement and strategic planning. So, assuming that a culture can be defined and that, once defined, it can be changed, we are likely long overdue to create a culture plan-especially if we want to improve the chances of success of our quality improvement and strategic plans!

\section{References}

1. Merriam-Webster dictionary. Merriam-Webster, Incorporated; 2015 [cited 2015 Feb 27]. Available from: www.merriam-webster.com/dictionary/culture

2. Ensom MHH. Forty-five years of the CJHP: Never closed, always renovating [editorial]. Can J Hosp Pharm. 2014:67(6):405-6.

3. Simonelli M. Culture eats innovation for lunch. Innovation Excellence; 2014 [cited 2015 Mar 1]. Available from: www.innovationexcellence.com/blog/ 2014/09/13/culture-eats-innovation-for-lunch/

4. Scott T, Mannion, R, Marshall M, Davies, H. Does organizational culture influence health care performance? A review of the evidence. J Health Serv Res Policy. 2003;8(2):105-17.

5. Rosenthal, MM, Hall K, Bussières JF, Tsuyuki R. Professional culture and personality traits of hospital pharmacists across Canada: a foundational first step in developing effective knowledge translation strategies. Can J Hosp Pharm. 2015;68(2):127-35.

6. Barry AR, Pearson, GJ. Professional use of social media by pharmacists. Can J Hosp Pharm. 2015;68(1):22-7.

7. Rosenthal MM, Breault RR, Austin Z, Tsuyuki RT. Pharmacists' self-perception of their professional role: insights into community pharmacy culture. $J \mathrm{Am}$ Pharm Assoc. 2011;51:363-7.

8. Jacobs S, Ashcroft D, Hassell K. Culture in community pharmacy organizations: What can we glean from the literature? J Health Organ Manag. 2011;25(4): 420-54.

Clarence Chant, PharmD, BCPS, FCCP, FCSHP, is Director of Pharmacy, St Michael's Hospital, Toronto, Ontario. He is also an Associate Editor with the CJHP.

Competing interests: None declared.

Address correspondence to:

Dr Clarence Chant

Pharmacy Department

St Michael's Hospital

30 Bond Street, Room B0007

Toronto ON M5B 1W8

e-mail : chantc@smh.ca

\section{ON THE FRONT COVER}

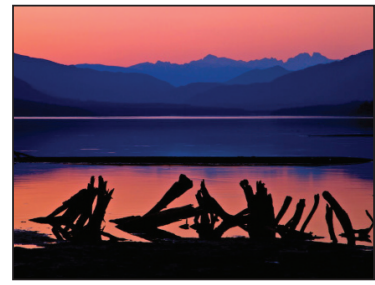

West Kootenay British Columbia

CSHP member Ken Wou (a Medication Quality Consultant for Alberta Health Services) captured this image in the West Kootenay, near Burton, British Columbia, using a Canon 7D camera with a 24-105 mm lens on a Gitzo tripod. "The waters were low at sunset, the hues were beautiful, and the silhouette of the floating tree stumps created some nice imagery."

The CJHP would be pleased to consider photographs featuring Canadian scenery taken by CSHP members for use on the front cover of the journal. If you would like to submit a photograph, please send an electronic copy (minimum resolution $300 \mathrm{dpi}$ ) to cjhpedit@cshp.ca. 